This is the accepted manuscript version of: Lodge, Chloe and Zloteanu, Mircea (2020) Jurors' expectations and decision-making : revisiting the CSI effect. The North of England Bulletin, 2020(2), pp. 19-30. 


\title{
Jurors' Expectations and Decision-Making: Revisiting the CSI Effect
}

\author{
Chloe Lodge $^{1} \&$ Mircea Zloteanu ${ }^{2}$ \\ ${ }^{1}$ Department of Psychology, Teesside University \\ ${ }^{2}$ Department of Criminology and Sociology, Kingston University London
}

\begin{abstract}
It has been argued that the rise in popularity of crime show dramas over the past few years has led to jurors holding unrealistic expectations regarding the type of evidence presented at trial. This has been coined the CSI effect. We investigated the CSI effect and the less well-known Tech effect-assigning more weight to evidence if obtained through technological meansand the impact of crime severity on juror decision-making. However, we argue that as time progresses, such effects will no longer be found to impact juror decision-making processes. We propose that past effects reported in the literature can be explained by considering a novelty bias. Using both frequentist and Bayesian frameworks, we tested this claim. Participants were primed with a newspaper that either contained a forensic, technology, or neutral article. They were then presented with two crime scenarios and asked to provide a verdict and a confidence rating. We find that mock jurors were unaffected by either the priming manipulation or crime severity, finding no evidence for either the CSI or Tech effects. The data suggest jurors are not as easily biased as has been previously argued in the literature, indicating a potential shift in public perceptions and expectations regarding evidence.
\end{abstract}

$* * * * *$

\section{Introduction}

The English legal system has relied on trial by juries for over eight centuries. In today's society, juries consist of twelve individuals randomly selected from the electoral register, who are required to deliberate on evidence and decide the guilt or innocence of a defendant (Gibson \& Cavadino, 2008). There are roughly 30,000 criminal cases that go to trial every year, resulting in around 40,000 juries being summoned per year (Willmott, Boduszek \& Booth, 2017). The legal system operates under the assumption that lay citizens can understand and utilize the evidence and legal arguments presented to them rationally and impartially, reaching an informed and objective verdict (Daftary-Kapur, Dumas, \& Penrod, 2010; Kassin \& Wrightmans, 2013). However, given the wide spectrum of individuals acting as jurors, it is reasonable to assume that various biases may impact the final judgment (Willmot et al., 2017). Research has highlighted that many factors such as the age of the defendant (Bergeron and McKelvie, 2004), the gender of the defendant (Lynch, Jewell, Wasarhaley, Golding \& Renzetti, 2017) and race of the defendant (Doerner \& Demuth, 2010) can bias the perceptions of juries and their verdicts. 
The type of evidence presented during a criminal trial can also influence the jury and affect the outcome (Daftary-Kapur, et al., 2010). Furthermore, jurors are unable to determine the accuracy or reliability of evidence presented to them (Nicholson, Yarbrough, \& Penrod, 2014), or disregard evidence which has been ruled inadmissible (Daftary-Kapur, et al., 2010). Of present importance, forensic evidence is highly influential to the juror decision-making process; this being linked to the portrayal of such evidence in modern media (e.g., Cole \& Dioso-Villa, 2009; Greene, 1990). For instance, Greene and Cahill (2012) found that, in cases where a defendant is deemed to be "high-risk" for future dangerousness, juries were more likely to seek the death penalty if they were also presented with neuroimaging evidence.

Scientific evidence can have an appreciable impact on jurors' decision-making, impacting how they view and weigh information. While the specifics for such effects are not yet fully understood, jurors may see such evidence as being more reliable or unbiased that other forms of evidence. Research suggests that jurors trust scientific evidence as it also provides a tangible physical explanation for the crime (Minott, 2013).

It has been argued that, in recent years, individuals' views and expectations of the type of evidence presented during trials has changed as a result of media and technology. The popularity of crime show dramas is proposed to have introduced a new bias into the criminal justice system: the CSI effect. The CSI effect suggests that fictional representations of criminal investigations and forensic evidence are altering jurors' perceptions of the criminal justice system (Hui \& Lo, 2017). Jurors are now holding exaggerated expectations for such scientific evidence to be collected and used during trial proceedings, and when it is absent jurors are more reluctant to award a guilty verdict (Hui \& Lo, 2017). Goodman-Delahunty and Tait (2017) argued that the CSI effect is fuelled by the expectation for forensic evidence to be present, rather than the viewing frequency of crime show dramas per se leading to a shift in judgment. However, the number of hours individuals spend watching crime show dramas does also correlate to their expectation for forensic evidence to be present during a trial (Tapscott, 2011) and to the likelihood of perceiving such evidence as being more reliable than testimonial evidence (Baskin \& Sommers, 2010).

This purported shift in jurors' expectations has produced increased concern among legal professionals, especially as it pertains to the burden of proof and reasonable doubt (Durnal, 2010). The fears have grown to such an extent that news outlets have been reporting on the alleged "CSI effect" as an unequivocal fact of juror decision-making processes (Cole \& Dioso-Villa, 2009). Due to its importance and media attention, researchers are giving considerable care to the potential impact of crime scene drama shows on jurors' decisionmaking (e.g., Smith, Patry, \& Stinson, 2017).

The argumentation emerging is that viewing CSI shows is interfering with jurors' decision-making ability (Sarapin \& Sparks, 2009). One potential explanation stems from cultivation theory (see Mosharafa, 2015), which suggests that exposure to television can result in an individuals' perceptions of reality conforming to what they are viewing on the screen (Cohen \& Wiemann, 2000). Linking this to the CSI effect, as individuals are viewing more crime show dramas, their beliefs and attitudes are mirroring what they see portrayed on television. Given that many of the shows within this genre sensationalize how evidence is 
collected and used in court (Rhineberger-Dunn, Briggs, \& Rader, 2016), individuals who watch the shows frequently may start to have a warped sense of reality and are naïve to the legitimate processes that occur in everyday life (e.g., Mancini, 2013). Although, the viewing frequency of such shows may be less important than the shift in the expectation of the quantity of evidence available during criminal trials. Hawkins and Scherr (2017) reported that the level of skepticism jurors had towards a case was related to the amount of evidence provided, not viewing patterns or the type of evidence. This highlights that an evidentiary threshold may be needed to be met and that jurors may hold an expectation that multiple forms of evidence will be presented.

While a meta-analysis by Eatley, Hueston, and Price (2016) concluded that the CSI effect has had an appreciable effect on the criminal justice system by altering jurors' expectations of evidence, empirical investigations have also produced conflicting evidence for the existence of the CSI effect (e.g., Call, Cook, Reitzel, \& McDougle, 2013, Klentz, Winters, Chapman, 2020; Podlas, 2006; Shelton, 2010). More recent explorations of the phenomenon had suggested that the concerns raised by others are unwarranted, finding no evidence for such an effect (Klentz et al., 2020).

A competing explanation for this trend in jurors' perception and expectation of evidence focuses on the role of scientific or technology-based evidence over more traditional form. The rapid development and proliferation of technology and access to information have been argued to be producing a "Tech effect" (Shelton, Kim, \& Barak, 2006). For instance, Kim, Barak, and Shelton (2009) found that jurors had raised expectations regarding scientific evidence being presented and were more likely not to convict if only circumstantial evidence was presented. They suggest this raised expectation is due to knowledge stemming from various sources regarding science and forensic psychology. Knowledge of forensic science and the techniques that are used are more readily available for the average person, suggesting that it is not crime show dramas that are influencing jurors (i.e. the CSI effect) but technology as a whole (i.e. a tech effect). Hui and Lo (2017) support this notion, finding that $89 \%$ of individuals expect scientific evidence to be presented during a trial. They note that individuals expect prosecutors and investigators to take advantage of the techniques available in today's society and use them within the criminal justice system.

An important observation emerging from the literature is that the strength of the findings and associated explanations of both the CSI and Tech effects seem to have shifted as time progresses (e.g., Shelton et al., 2006; Kim et al., 2009 \& Hui and Lo, 2017). We propose that the mixed and contradictory findings can be explained by the role of novelty on perception and judgment. Novelty tends to affect which information people focus on, the weight they assign to this information, and the likeability of said information over other more traditional sources. For instance, Wells, Campbell, Valacich, and Featherman (2010) focused on the effect of novelty on individuals adopting new information technology (IT) innovations in terms of risk/reward. They found that perceived novelty plays a vital role in the adoption of IT innovations. This highlights that novelty drives attention and adoption of new elements in society. Linking this to the CSI and Tech effect, past reported effects may reflect the novelty of forensic science in the mind of the public, leading to the (temporary) impact on 
juror decision-making. Novelty and newness are often related to the adoption of technology and trends in daily life and wider culture (Park \& Chen, 2007), and the interest people have towards such innovations (Adachi, Ryan, Frye, McClurg \& Rigby, 2017). The discrepancy in the reported literature on the CSI and Tech effects may simply reflect the public's habituation to the technology and procedures depicted in the media, leading to a decrease, if not complete elimination, of the previous effect(s) (Georgiev, 2018). The possibility exists that the CSI and Tech effects are temporary phenomena (triggered by their novelty) and over time they begin to lose their impact.

Given the importance placed on jurors within the justice system, and the gravity behind their decisions, it is pertinent to explore factors that may be biasing their judgments and ultimate verdicts. Presently, we consider a newer exploration is warranted, examining whether the impact of CSI related media and Technology-based evidence still influence juror decision-making or if, indeed, such effects do not have the dramatic impact previously reported. We investigated the impact of priming potential jurors with either CSI and Tech related information on their verdict decisions and judgment confidence. Second, we considered the impact of the type of crime on judgment, as different crimes relate to different base-line expectations of specific evidence (Shelton, et al., 2006). We assessed if the type of crime - violent or non-violent - impacts juror decision-making and evidence expectation. It was predicted that the type of crime will impact the evidence jurors use to reach their decisions. Specifically, when presented with a violent crime, jurors' expectation of forensic evidence will be higher than when presented with a non-violent crime. However, it was predicted that priming jurors with either CSI or Tech related information would not appreciably bias their decisions.

\section{Method}

\section{Participants}

An opportunity sampling technique was used. To improve ecological validity, the inclusion criterion followed the legal requirements for jury service (HM Courts \& Tribunals Service, 2017). The sample consisted of 95 individuals. The attrition rate for the study was $2.1 \%$ as some participants failed to fully complete the study, resulting in a final sample of 92 individuals (72 females and 20 males; Age range: $18-75 ; M_{\text {Age }}=27.2, S D=10.6$ ).

\section{Stimuli}

Three newspaper articles were created (see Figure 1). The use of fake newspaper articles to prime participants is a common methodology used to investigate the CSI effect (Hawkins \& Scherr, 2017). The "Technology" article focused on Cleveland police's new computer system, expressing how it had improved evidence collecting and investigations. The "Forensic" article lauded the advancements made in forensic testing made by Cleveland Police. The "Neutral" article focused on a charity event organized by Cleveland police. 


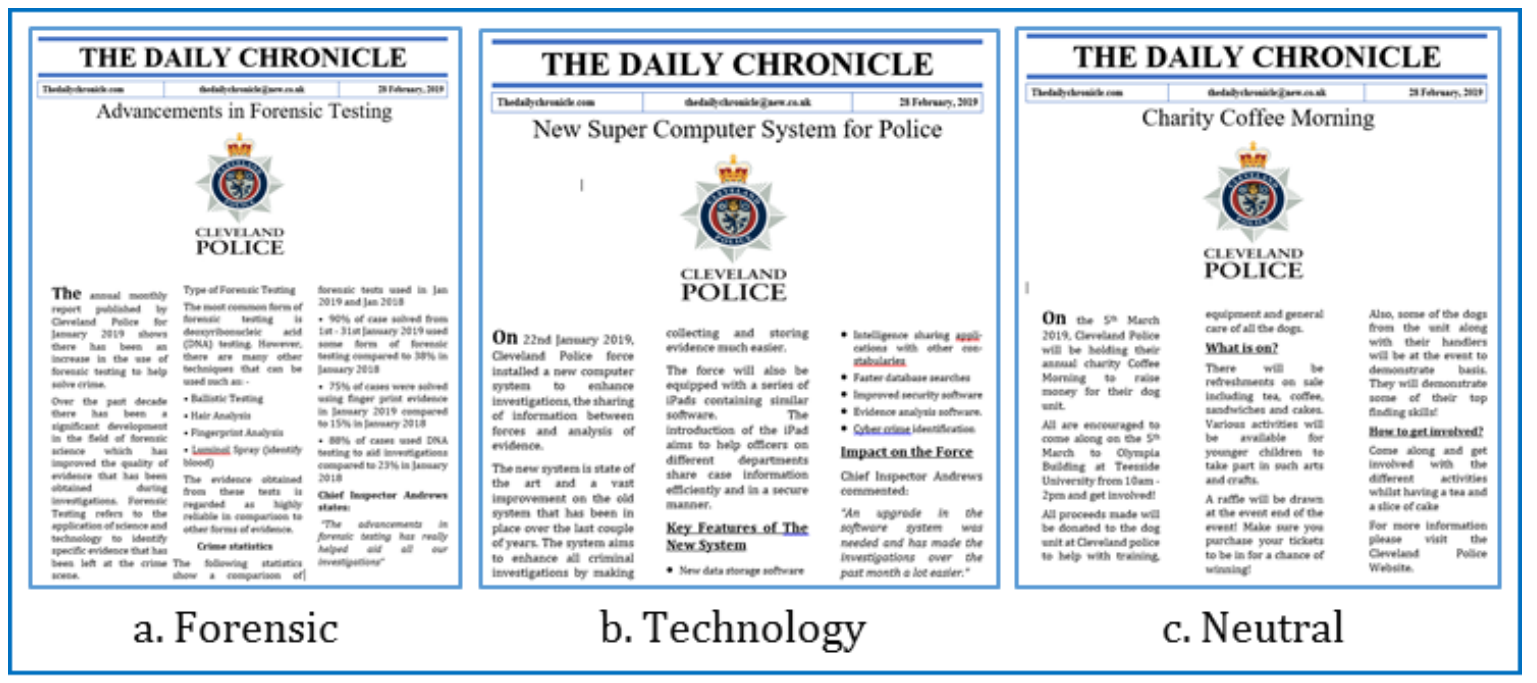

Figure 1. News articles used in the experiment.

For the case related information, two vignettes were created. The "burglary case" vignette included the name, age, and gender of the defendant, details of the crime they are accused of, and three different forms of evidence found by the police. These were an eyewitness account, a form of forensic evidence (a fingerprint analysis) and a piece of circumstantial evidence (a large sum of money found in the defendant's possession). The "murder case" vignette included the name, age, and gender of the defendant, details of the crime they are being accused of, alongside three different forms of evidence found by the police (eyewitness, forensic and circumstantial). Here, the forensic evidence was a DNA analysis, while the circumstantial evidence a single glove matching a pair the defendant owns. Both eyewitness accounts place the defendant at the scene of the crime around the time the offense occurred. In both cases, the defendant was depicted as male in his early thirties and denied the charges against him.

\section{Design and Procedure}

A factorial mixed-design was used, with News Article (Forensic, Technology, Neutral) as the between-subjects factor, and Crime Type (Murder vs Burglary) as the withinsubjects factor. The two dependant measures were verdict (forced-choice binary) and confidence rating (Likert scale).

Participants were tested online using the JISC Survey platform. The questionnaire was distributed via social media, email, and using Teesside University's SONA system. Participants were prompted with a consent form and information sheet describing the study. After giving consent, they were randomly allocated to one of the three experimental conditions, Forensic, Technology, or Neutral, and required to read the fake newspaper article (condition-specific). Once they had finished reading the article, they were asked to read the first trial vignette (counterbalanced between participants) and asked to respond to several questions. They were then presented with the second vignette. For the burglary case they were asked to state if they felt the defendant was "guilty" or "not guilty", state how confident they were in their verdict (using a 5-point Likert scale) and specify which type of evidence they relied on to make the decision phrased as "Which type of evidence did you rely on most 
when making your decision?" (Options: Eyewitness Account, Large Sum of Money Found, Fingerprint Evidence). For the murder case they were asked to state if they felt the defendant was "guilty" or "not guilty", state they confidence in the verdict, and state which type of evidence they used to come to the decision; here the options were Eyewitness Account, Glove Evidence, DNA evidence.

Following this, they were asked how often they watched crime-based television shows. The post-test questions were created to understand participant's television viewing habits, assess if participants were aware of different types of evidence, and the perceived reliability of each form of evidence. They were asked to state if they were aware of the concepts of the following type of evidence: DNA, fingerprint analysis, hair fiber analysis, eyewitness testimony and circumstantial evidence. Based on their answers, they were then asked how reliable they felt that type of evidence was. Participants were then debriefed. The study took around twenty minutes to complete. The study had full ethical approval from the School of Social Sciences, Humanities, and Law at Teesside University (SSSBLRECSTUD2373).

\section{Results}

\section{Verdict}

An analysis was conducted to assess priming jurors with certain information affected verdicts, while also considering the severity of the crime. A generalized estimating equation (GEE) considering Crime Type (Murder vs Burglary) and News Article (Forensic, Technology, Neutral) was used to analyze the verdicts awarded by the mock jurors; the "Neutral article" and "Burglary case" were used as reference categories. The analysis revealed no statistically significant difference in verdicts between the two Crime Type cases, in either Forensic, $\operatorname{Exp} B=.696$, Wald $\chi^{2}(1)=.216, p=.642,95 \%$ CI [.07, .45], Technology, $\operatorname{Exp} B=.859$, Wald $\chi^{2}(1)=.044, p=.834,95 \%$ CI [.21, 3.54], or Neutral conditions, ExpB= 1.243, Wald $\chi^{2}(1)=.091, p=.763,95 \%$ CI [.30, 5.11]. Considering News Article, there was no statistically significant difference between Murder and Burglary verdicts, in the Forensic condition, $\operatorname{Exp} B=1.582$, Wald $\chi^{2}(1)=.471, p=.493,95 \%$ CI $[.43,5.86]$, or in the Technology condition, $\operatorname{Exp} B=.193$, Wald $\chi^{2}(1)=2.130, p=.144,95 \%$ CI $[.02,1.76]$. The interaction term between Crime Type and News Article was not found to be statistically significant, Wald $\chi^{2}(5)=4.49, p=.481$.

The data were also analyzed with a Bayesian generalized mixed-effects model, using the brms package (Burkner, 2018) in R 3.6.2 (R Core Team 2020). This provided supporting evidence for no difference between the experimental conditions in terms of verdicts given (see Table 1).

Table 1.

Parameter Estimates, Estimation Error, and 95\% Credible Interval

\begin{tabular}{lcccc}
\hline & Estimate & EE & \multicolumn{2}{c}{$95 \%$ CrI } \\
\hline Intercept & $\mathbf{- 2 . 1 0}$ & $\mathbf{0 . 7 4}$ & $\mathbf{- 3 . 8 2}$ & $\mathbf{- 0 . 9 2}$ \\
Tech & -0.61 & 0.95 & -2.58 & 1.15 \\
CSI & -0.86 & 1.00 & -2.96 & 0.94 \\
Burglary & -0.30 & 0.75 & -1.80 & 1.15
\end{tabular}


$\begin{array}{lllll}\text { Tech:Burglary } & -1.94 & 1.69 & -5.77 & 0.95\end{array}$

$\begin{array}{lllll}\text { CSI:Burglary } & 1.44 & 1.18 & -0.82 & 3.84\end{array}$

Note. $N=92, E E=$ estimation error, $C r I=$ credible interval

\section{Confidence}

An analysis was also conducted to assess if being primed with certain information affected mock juror's confidence in the verdicts they awarded. A repeated measures ANOVA was used to analyse differences in verdict confidence based on News Article and Crime Type. This revealed no main effect of Crime Type, $F(1,90)=.367, p=.546, \mathrm{JZS} \mathrm{BF}_{10}=$ $0.19^{1}$ or no main effect for News Article $F(2,90)=.132, p=.876, \mathrm{JZS} \mathrm{BF}_{10}=0.15$. There was also no significant interaction of crime type and news article on individual's confidence ratings $\left(F(2,90)=.105 p=.900, \mathrm{JZS} \mathrm{BF}_{10}=0.12\right)$.

\section{Evidence}

Chi-square tests were initially conducted on the knowledge of evidence responses. These revealed no statistically significant differences in knowledge of the five types of evidence between the News Article groups, $\chi^{2}(2) \mathrm{s} \leq 1.81, p \geq .405, \mathrm{JZS} \mathrm{BF}_{10} \leq 0.95$. Subsequently, several ANOVAs were used to investigate difference in ratings of reliability for the different types of evidence based on News Article groups. No statistically significant differences were found for DNA evidence, $F(2,86)=.543, p=.583, \mathrm{JZS} \mathrm{BF}_{10}=0.15$, fingerprint evidence, $F(2,88)=.853, p=.430, \mathrm{JZS} \mathrm{BF}_{10}=0.20$, hair fibre evidence, $F(2,72)=$ 4.751, $p=.014, \eta^{2}=.113, \mathrm{JZS} \mathrm{BF}_{10}=3.66$ (non-significant after Bonferroni corrections, however Bayes factor indicates moderate support in favour of a difference), eyewitness evidence, $F(2,86)=.131, p=.878, \mathrm{JZS} \mathrm{BF}_{10}=0.11$, or circumstantial evidence, $F(2,61)=$ $.237, p=.790, \mathrm{JZS} \mathrm{BF}_{10}=0.15$.

Unpacking the hair fibre effect, post hoc comparisons (Tuckey-corrected) find that compared to the Neutral condition, participants in the CSI condition rated the reliability of such evidence significantly more highly, $t(48)=2.82, p=0.017,95 \%$ CI [2.20, 26.89], $d=$ $.77, \mathrm{JZS} \mathrm{BF}_{10}=5.28$. A similar result was observed for the Tech condition, $t(49)=2.32, p=$ $0.059,95 \%$ CI $[-0.36,24.08], d=.06, \mathrm{JZS} \mathrm{BF}_{10}=1.61$, however the data does not show strong support for a difference. The difference between CSI and Tech conditions was in the expected direction, but not substantial, $t<1, p=0.864,95 \%$ CI $[-9.78,15.15], \mathrm{JZS} \mathrm{BF}_{10}=$ 0.34 .

No differences in television usage between the three News Article groups was found, $\chi^{2}(8)=6.88, \mathrm{p}=.550, \mathrm{JZS} \mathrm{BF}_{10}=0.05$. The majority rated their viewing habit as "often" (45\%), followed by "sometimes" (21\%), "rarely" (17\%), and "always" (11\%), while only 4\% selecting "never".

Finally, considering which evidence type was selected by jurors as being most relevant for their decision-making, chi-square tests were conducted for the Burglary case and

\footnotetext{
${ }^{1}$ The Bayes Factor is calculated to indicate evidence in favour of the alternative hypothesis $\left(\mathrm{H}_{\mathrm{a}}\right), \mathrm{BF}_{10}$, however, if readers wish to read this as evidence in favour of the null (i.e. no effect; $\mathrm{H}_{0}$ ), the values can be transformed by taking $1 / \mathrm{BF}_{10}=\mathrm{BF}_{01}$. For example, $\mathrm{BF}_{01}=1 / 0.19=5.26$, suggesting the evidence if over 5 times more likely under the null.
} 
the Murder case. For burglary, there were no differences in which evidence was used to make the decision, $\chi^{2}(4)=.99, p=.910, \mathrm{JZS} \mathrm{BF}_{10}=0.33$, with jurors in all conditions selecting Forensic evidence over $75 \%$ of the time. For murder, similarly, no differences were found, $\chi^{2}$ $(4)=2.53, p=.639, \mathrm{JZS} \mathrm{BF}_{10}=0.09$, with most jurors selecting Forensic evidence (over $85 \%$ ) regardless of news article condition.

\section{Discussion}

The current study investigated the alleged impact of the "CSI effect" and "Tech effect" on juror decision-making in light of the novelty of such phenomena having diminished in past years. There were two main aims with the present research. Firstly, to determine if juries were affected by watching crime-based television programs (i.e. CSI effect) or by the development of technology in the forensic field (i.e. Tech effect). Secondly, to assess if the severity of the crime (violent or non-violent) affected the type of evidence they jurors relied on to make their decisions.

In line with our predictions, we found no evidence of a CSI or Tech effect impacting jurors' decision-making, either concerning verdict or judgment confidence. In contrast to our second prediction, no evidence was found that the type of crime affected which type of evidence jurors rely on more to reach their verdicts. This suggests that despite being primed with either the CSI or tech-related information, jurors' decision-making and judgment confidence was unaffected, contrasting past findings on the CSI effect (e.g., Kim et al., 2009), and paralleling research indicating a decrease in such effects on judgment (e.g., Hui \& Lo (2017). Tentatively, this may be taken to support our assertion that CSI and Tech related biases once observed in the literature were more likely due to a novelty or salience bias than to an underlying psychological effect.

Linking this back to cultivation theory, which argues that people believe what they see portrayed on television is an accurate version of reality, it could be that individuals no longer hold exaggerated expectations regarding forensic evidence. Although the current study asked participants if they watched crime show dramas (with the majority stating they often watch them), it did not directly consider if the shows participants watch were more factual or fictional. Future research should focus on assessing if the type of crime shows individuals watch affect their decisions or makes them more susceptible to the CSI or tech effect. One approach may be to have participants watch an episode of various shows, to have a more multi-modal approach to the priming manipulation.

Here, despite being primed before reading the case information, jurors' responses did not show appreciable differences. The current results should prompt new investigations into purported cultural or societal effects on jury decision-making, and consider more strongly the theoretical underpinning of past claims. The findings illustrate the need to ensure we have an accurate and clear understanding of the effects which can bias jurors' perceptions and verdicts. Our results alleviate some of the concerns regarding CSI television show on expectations of evidence and ultimate decision-making decisions.

In the present data, crime type was also not found to affect juror's verdict or confidence. This is interesting as it differs from previous research on mock jurors, which 
finds harsher penalties awarded for more serious crimes (Walker \& Woody, 2011). At present this can be explained by a potential ceiling effect in our data, as the majority of participants considered both suspects to be guilty of their crime. The lack of an interaction effect between crime type and the priming manipulation highlights that under scenarios where the cases may strongly favor a guilty verdict, the evidence type and juror expectations do not play a significant role. Future studies may aim to modify the ambiguity or complexity of the case information to understand if the biasing effects only occur under situations of uncertainty. At present, it can be taken that such biasing effects are not impactful when the evidence provides is clear. That said, the vast majority of participants selected "forensic evidence" as being the primary source of information driving their verdict. This interpretation is tentatively corroborated by the hair fiber results indicating that when primed with CSI related information, jurors do assign stronger reliability to evidence that is typically associated with crime scene shows. Thus, while being primed with specific forms of information may have an impact on how evidence is perceived and weighed, the case specifics are more pertinent to the final verdict.

In support of our novelty hypothesis, our current sample self-reported a high level of awareness of various types of evidence (DNA, fingerprint analysis and hair fiber analysis, eye witness testimony and circumstantial evidence). This level of knowledge may have contributed to the lack of effects from our manipulations and would fit our prediction that with time the novelty of forensic tools diminishes, and with it, the effects reported in past research. Participants did indicate they felt that the forensic evidence was more reliable compared to the testimonial or circumstantial evidence, which mirrors past findings (Lieberman, Carrell, Miethe, \& Krauss, 2008). It is not surprising that jurors rely on what they perceive to be scientific-based evidence given the weight and implications of their verdicts (Mann, 2005).

The study contributes to the existing literature, arguing that jurors are not as influenced by outside factors as previously suggested. For the criminal justice system, this highlights the need for stronger theoretical underpinnings in research on perceptions, expectations, and biases. Although new effects and phenomena can pique interest, alternative, and more well-established explanations must first be considered. Here, we argue and find support for an alternative explanation for the alleged CSI/Tech effect using the literature on novelty and salience. The steady trend in the literature for a decrease in the magnitude of the effect over time reflects our assertions. To clarify, we do not argue that the weight of forensic and technology-based evidence will diminish over time, we simply propose that the expectations and impact of such evidence on verdicts will change as society adapts to forensic advancements. However, given individuals unquestioning trust in forensic-based evidence, the next issue may be to provide greater transparency regarding the strengths and weaknesses of such evidence to ensure a fair and objective process.

\section{Conclusion}

The current research investigated whether mock jurors were influenced by CSI or Tech related priming effects when deliberating on violent and non-violent crimes. We framed the study by arguing for an alternative explanation for such biasing effects than that proposed 
by past research: novelty and saliency. As time progresses, and society adapts to the advances in forensic science these purported effects should diminish. Indeed, our findings support this prediction. We found no evidence of either the CSI effect or Tech effect impacting verdicts or judgment confidence. Surprisingly, we also found that crime severity is not a factor impacting either verdict, confidence, or type of evidence utilized. Indeed, the majority of participants preferred forensic evidence when making decisions, and considered hair fiber evidence as being more reliable when first primed with CSI related information. Taken together, this illustrates that research must be mindful of the underpinning of the effects it considers in jury decision-making research and the need for careful investigations into the temporal aspects of such effects. 


\section{References}

Adachi, P. J., Ryan, R. M., Frye, J., McClurg, D., \& Rigby, C. S. (2018). "I can't wait for the next episode!" Investigating the motivational pull of television dramas through the lens of self-determination theory. Motivation Science, 4(1), 78.

Baskin, D. R., \& Sommers, I. B. (2010). Crime-show-viewing habits and public attitudes toward forensic evidence: The "CSI effect" revisited. Justice System Journal, 31(1), 97-113.

Bergeron, C. E., \& McKelvie, S. J. (2004). Effects of defendant age on severity of punishment for different crimes. The Journal of Social Psychology, 144(1), 75-90.

Bürkner, P. C. (2018). Advanced Bayesian Multilevel Modeling with the R Package brms. The R Journal, 10 (1), 395-411. doi: 10.32614. RJ-2018-017.

Call, C., Cook, A. K., Reitzel, J. D., \& McDougle, R. D. (2013). Seeing is believing: the CSI effect among jurors in malicious wounding cases. Journal of Social, Behavioral, and Health Sciences, 7, 52-66. doi:10.5590/JSBHS.2013.07.1.04

Cohen, J., \& Weimann, G. (2000). Cultivation revisited: Some genres have some effects on some viewers. Communication Reports, 13(2), 99-114.

Cole, S. A., \& Dioso-Villa, R. (2009). Investigating the 'CSI Effect' effect: media and litigation crisis in criminal law. Stanford Law Review, 61, 1335-1373.

Daftary-Kapur, T., Dumas, R., \& Penrod, S. D. (2010). Jury decision-making biases and methods to counter them. Legal and Criminological Psychology, 15, 133-154. doi: $10.1348 / 135532509 \times 465624$

Doerner, J. K., \& Demuth, S. (2010). The independent and joint effects of race/ethnicity, gender, and age on sentencing outcomes in US federal courts. Justice Quarterly, $27(1), 1-27$.

Durnal, E. W. (2010). Crime scene investigation (as seen on TV). Forensic Science International, 199, 1-5. doi:10.1016/j.forsciint.2010.02.015

Eatley, G., Hueston, H. H., \& Price, K. (2016). A meta-analysis of the CSI effect: The impact of popular media on jurors' perception of forensic evidence. Politics, Bureaucracy, and Justice, 5, 1-10.

Gibson, B., \& Cavadino, P. (2008). The criminal justice system: An introduction Waterside Press.

Goodman-Delahunty, J., \& Tait, D. (2017). CSI effects on jury reasoning and verdicts. Juries, science and popular culture in the age of terror (pp. 217-233) Springer

Gunnell, J. J., \& Ceci, S. J. (2010). When emotionality trumps reason: A study of individual processing style and juror bias. Behavioral Sciences \& the Law, 28(6), 850-877. 
Greene, E. (1990). Media effects on jurors. Law and Human Behavior, 14, 439-450. doi:10.1007/bf01044221

Greene, E., \& Cahill, B. S. (2012). Effects of neuroimaging evidence on mock juror decision making. Behavioral Sciences \& the Law, 30(3), 280-296.

Hawkins, I., \& Scherr, K. (2017). Engaging the CSI effect: The influences of experiencetaking, type of evidence, and viewing frequency on juror decision-making. Journal of Criminal Justice, 49, 45-52.

HM Courts \& Tribunals Service (2017). Guide to Jury Summons. Retrieved from https://assets.publishing.service.gov.uk/government/uploads/system/uploads/attachme nt_data/file/709844/jury-summons-guide-eng.pdf

Hui, C. Y., \& Lo, T. W. (2017). Examination of the "CSI effect" on perceptions of scientific and testimonial evidence in a hong kong chinese sample. International Journal of Offender Therapy and Comparative Criminology, 61(7), 819-833.

Kassin, S. M., \& Wrightsman, L. S. (2013). The american jury on trial: Psychological perspectives Taylor \& Francis.

Klentz, B. A., Winters, G. M., \& Chapman, J. E. (2020) The CSI Effect and the impact of DNA evidence on mock jurors and jury deliberations. Psychology, Crime \& Law, 119. doi:10.1080/1068316X.2019.1708353

Kim, Y. S., Barak, G., \& Shelton, D. E. (2009). Examining the "CSI-effect" in the cases of circumstantial evidence and eyewitness testimony: Multivariate and path analyses. Journal of Criminal Justice, 37(5), 452-460

Lieberman, J. D., Carrell, C. A., Miethe, T. D., \& Krauss, D. A. (2008). Gold versus platinum: Do jurors recognize the superiority and limitations of DNA evidence compared to other types of forensic evidence? Psychology, Public Policy, and Law, 14(1), 27.

Lynch, K. R., Jewell, J. A., Wasarhaley, N. E., Golding, J. M., \& Renzetti, C. M. (2017). Great sexpectations: The impact of participant gender, defendant desirability, and date cost on attributions of a date rape victim and defendant. Journal of Interpersonal Violence, , 0886260517709800.

Mancini, D. E. (2013). The" CSI effect" in an actual juror sample: Why crime show genre may matter. North American Journal of Psychology, 15(3)

Mann, M. (2005). The CSI effect: Better jurors through television and science. Buff.Pub.Int.LJ, 24, 211.

Minott, T. (2013). Born this way: How neuroimaging will impact jury deliberations. Duke L.\& Tech.Rev., 12, 219.

Mosharafa, E. (2015). All you need to know about: The cultivation theory. Global Journal of Human-Social Science: A, Arts \& Humanities-Psychology, 15(8), 22-37. 
Nicholson, A. S., Yarbrough, A. M., \& Penrod, S. D. (2014). Jury Decision Making and Eyewitness Testimony. Encyclopedia of Criminology and Criminal Justice, 27272735. doi:10.1007/978-1-4614-5690-2_670

Park, Y., \& Chen, J. V. (2007). Acceptance and adoption of the innovative use of smartphone. Industrial Management \& Data Systems.

Podlas, K. (2006). "The CSI Effect": exposing the media myth. Fordham Intellectual Property Media \& Entertainment Law Journal, 16, 429-465.

Rhineberger-Dunn, G., Briggs, S. J., \& Rader, N. E. (2016). The CSI effect, DNA discourse, and popular crime dramas. Social Science Quarterly, 98, 532-547.

doi:10.1111/ssqu.12289

Sarapin, S. H., \& Sparks, G. G. (2009). Eyewitnesses to TV versions of reality: The relationship between exposure to TV crime dramas and perceptions of the criminal justice system. How Television Shapes our Worldview: Media Representations of Social Trends and Change, , 145-170.

Schweitzer, N. J., \& Saks, M. J. (2006). The CSI effect: Popular fiction about forensic science affects the public's expectations about real forensic science. Jurimetrics, 47, 357.

Shelton, D. E. (2010). Juror expectations for scientific evidence in criminal cases:

Perceptions and reality about the CSI effect myth. Cooley Law Review, 27, 1-35.

Shelton, D. E., Kim, Y. S., \& Barak, G. (2006). A study of juror expectations and demands concerning scientific evidence: Does the CSI effect exist. Vand. J. Ent. \& Tech. L., 9, 331.

Smith, S. M., Patry, M. W., \& Stinson, V. (2017). But what is the CSI Effect? How crime dramas influence people's beliefs about forensic evidence. Canadian Journal of Police and Security Services, 5, 187-195.

Tapscott, R. (2011). Media effects and the criminal justice system: An experimental test of the CSI effect.

Team, R. C., Bivand, R., Carey, V. J., DebRoy, S., Eglen, S., Guha, R., ... \& Pfaff, B. (2020). Package 'foreign'.

Thomas, C. A., \& Balmer, N. J. (2007). Diversity and fairness in the jury system Ministry of Justice.

Walker, C. M., \& Woody, W. D. (2011). Juror decision making for juveniles tried as adults: The effects of defendant age, crime type, and crime outcome. Psychology, Crime \& Law, 17(8), 659-675.

Wells, J. D., Campbell, D. E., Valacich, J. S., \& Featherman, M. (2010). The effect of perceived novelty on the adoption of information technology innovations: a risk/reward perspective. Decision Sciences, 41(4), 813-843. 
Willmott, D., Boduszek, D., \& Booth, N. (2017). The english jury on trial. Custodial Review, $82,12-14$. 